\title{
EL REFRANERO DE LUIS GALINDO Y LOS ADAGIA DE ERASMO
}

Pilar Vega Rodríguez

Universidad Complutense de Madrid

Las Sentencias filosóficas y verdades morales que otros llaman proverbios y adagios castellanos, ms. inédito en diez tomos de la BNM, núms. 97779781 , son un repertorio de refranes glosados reunido hacia 1650 por el ocaniense doctor en leyes y abogado de los Reales Consejos, Luis Galindo. La importancia de esta colección, hasta ahora olvidada en razón de su inabarcabilidad, estriba en la importancia de sus materiales y el seguimiento de modelos tan señeros como Erasmo.

En efecto, las fuentes paremiológicas latinas del ms. de Luis Galindo proceden en su mayoría de los Adagiorum Chiliades Quatuor. Otras colecciones que inspiraron el caudal paremiológico del refranero de Luis Galindo se nutren asímismo de la veta erasmista, como es el caso de los refranes de Hernán Núñez (1555), la Filosofía vulgar de Juan de Mal Lara (1568), y los Adagialia Sacra del P. Martín del Río (1612). De otra parte, algunas citas pseudoproverbiales, versos de Terencio, Plauto, Catón, Virgilio, etc., se han extractado a partir de los Adagios de Erasmo. Luis Galindo demuestra conocer además los Diálogos, Paráfrasis evangélicas y, concretamente, las Similitudines de donde proceden las simbologías y comparaciones poéticas de la obra. También de Erasmo se extraen tópicos filosóficos. Puede decirse, en fin, que la filiación erasmista de este repertorio, entendida como préstamo de materiales con o sin transmisión ideológica, es algo evidente. 


\section{LOS ADAGIA Y LAS COLECCIONES ESPAÑOLAS DE PAREMIOLOGÍA}

Se ha discutido sobre el protagonismo de la colección erasmiana en la evolución de la paremiología española ${ }^{1}$.

En el siglo XVI se consolida un proceso de dignificación proverbial que aporta al refrán antiguo la veneración renacentista por los productos populares. Una orientación netamente erasmista propicia en este momento el cotejo de las unidades repertoriadas en los Adagia con los proverbios castellanos, fenómeno prontamente iniciado, como atestiguan los ejemplares de las primeras ediciones ${ }^{2}$.

En este clasicismo, los Adagia juegan un papel primordial. No sólo facilitan la aspiración clásica de las lenguas romances, por la proposición de cotejos con los monumenta literarios, sino que inauguran un procedimiento de exégesis paremiológica e instauran el sistema organizativo de las colecciones. Los refraneros del siglo de Oro, más adelante, no sólo dependen de Erasmo estructuralmente: asimilarán también los procedimientos de recopilación a la vez que gran parte de sus materiales.

1 Según L. COMBET, el repertorio de Erasmo no habría hecho sino ordenar esta gran masa de materiales de derrubio sentencioso, condensando el saber antiguo esparcido en millares de volúmenes: Recherches sur le refranero castilian au Moyen âge, Burdeos, 1971, p. 134. Sin la compilacín de Erasmo hubiera sido difícil que las colecciones paremiologicas del siglo XVI hubiesen tomado el relieve necesario hasta llegar a su sistematicidad. Según E. O'KaNE, Refranes y frases proverbiales españolas de la Edad Media, Anejos del BRAE, II, 1959, p. 37, la influencia de la paremiología medieval española fue superior y más duradera que la ejercida por el erudito holandés. Los grandes refraneros áureos habrían tenido lugar sin la intervención de Erasmo.

2 En el ejemplar de la Biblioteca Pública del Estado de León, sig. 24/6321, de la edición de Colonia, 1533, hay abundantes notas manuscritas en letra humanista que iluminan los adagios ya desde el índice analítico. Los ejemplos son los siguientes: Ad felicem inflectere parientem. $\mathrm{Ni}$ a quien vence. Caliga Maximi. Caliga cognosco como blanca de hilo. Capram portare non possum et imponitis bovem. A mí no puedo y a mis comadres hilo. Multa cadunt inter calicem supremaque labra, multa cadunt. Aún está el rabo por desollar. Multa e rota voluentur. Más días ay que longaniças. Multitutdo imperatorum cariam perdidit, Asno de muchos, lobos lo comen. Non curat numerus lupus... de las contadas come el lobo. Non statim finis apparet. No se ganó Çamora en un hora. Oboedientia felicitatis ma... Vecerrica mansa tudas las bacas mama. Pereant amici... Daría io un ojo porque a mi enemigo le sacase sendos. Pinum in morem. No le agudado esta la empare. Rosam quae praeterit, ne queras iterum. Con agua pasada no mueve el molino. Ubi pueris impera. Mandad a vuestros moços.

En el texto: Infixo aculeo fugere. Chil. 1. cent. 1. cp. 5: «nos dicimus Tirar la piedra i esconder la manom. Otra nota a Chil. 1. cent. 4. cp. 39, Praeclarissimam hominem eruditionem. Y en Quod non opus et, asse charum est. Chil. 4. cent. 3 . cp. 99 . Hisp. Compra caro quien compra lo que no ha menester. O en Manuum admouenti fortuna est implorande. Chil. 2. cent. 2. cp. 81 «nos dicimus: a Dios rogando i con el mazo dandom. 
Además de un simple modelo compositivo, los Adagios se demostraron extraordinariamente eficaces en la expansión del erasmismo ${ }^{3}$, razón que explica su temprana censura, pues ya las ediciones de Frobenius (1517-1518) expresan con excesiva libertad observaciones del autor. Algunos adagios, singularmente ideologizados, Scarabeus, Sileni Alciabiadis, Dulce bellum inexpertis, pequeños ensayos de réplica erasmista, se editaron en solitario ${ }^{4}$. A juzgar por la supervivencia de ejemplares no censurados, y la multitud de ediciones, la difusión de los Adagios fue extraordinaria ( $E . y E$., 160), hasta el punto de que pueden reconocerse filiaciones erasmistas en muchos autores aparentemente no comprometidos con el holandés 5 .

Sobre los adagios de Erasmo se formaron otros registros de proverbios, tanto en España con el Diccionario de Sánchez de la Ballesta (1587) como en otros países. Algunos ejemplos de la propensión adagiaria son el Thrésor de Gabriel Meurier (1577) ${ }^{6}$, el Bouquet de philosophie morale (1617), el Trésor de sentences dorées et argentés (1617), y el Miroir de Jacques Cate (1635), afirma Duplessis ${ }^{7}$. Grynnaeus ${ }^{8}$, ya tardíamente, (1649), intentó redistribuir los

${ }^{3}$ Como en los Refranes de Francisco de Espinosa (1547). Según E. O'Kane la influencia de Erasmo en Espinosa no se limita a la filiación ideológica en las cuestiones sobre el culto, la libertad de espíritu, la fe dubitativa, el naturalismo y la visión negativa del matrimonio, sino que se extiende a la concepción de nuevos géneros como la combinación que había ideado de adagios y apotegmas. Refranero, ed. Madrid, Anejos del BRAE, XVIII, 1968, 16-17. La Bibliotheca Erasmiana de F. VANDER HAEGHEN, Gand, 1987, detalla 27 ediciones de los Adagios en vida de Erasmo. Bataillon considera que esta obra es una fuente importante para calibrar la ideología y el estilo de Erasmo, E. y E., 137. Bibliographie des oeuvres d'Erasme. Separata de la Biblioteca Bélgica publicada por F. Vander Haeghen, R. Vanden Berghe, T. J. I. Arnol y A. Roersch Gand, 1897-1915. Adagia 1897, 2. Ap. 1901.

4 M. Bataillon, Erasmo y España. Estudios sobre la historia espiritual del siglo XVI. trad. A. Alatorre, Méjico-Buenos Aires, FCE, primera reimpresión, 1979, abreviadamente: $E$. $E$., señala que estos adagios iniciaron a los paremiólogos en los procedimientos de la glosa. $E$. y $E$., 673. Entre las ediciones aisladas del adagio Bellum, se cuenta la traducción alemana de 1519, e inglesa, 1533-34. Circuló como folleto de propaganda en inglés, francés y holandés. R. Dumil-Marque, «Remarque historique de l'adage 300 de Erasme Dulce Bellum inexpertis», Symposium, VIII, 1954, 151-157. De los Sileni Alciabiadis hay traducciones castellanas: Bernardo Pérez Chinchón, Valencia, Jorge Costilla, 1529; Amberes, Martín Nucio, 1555.

5 Remito al estudio del profesor Antonio Vilanova, Erasmo y Cervantes, Barcelona, Lumen, 1989, donde se analizan estas y otras eventuales influencias.

- Thrésor de sentences dorées, dicts, Proverbes et Dictons communs réduits selon l'ordre alphabetique, avec le bouquet de philosophie moral, Lyon, Jean d'Onegolles, 1577. Id. Rouen Nicolas Lesayes, 1577, Id. réduit par Demandes et Reponses, G. Rouen Mic Lessayes, 1579.

7 Cfr. G. Duplessis, Bibliographie paréjologique, París, 1847, n. 164.

8 Adagia id est, Proverbiorum Paroemiarum, et Parabolarum omnium quae apud Graecos, Latinos, Haebreos, Arabas... in usu fuerunt, collectio absolutissima in locos communes digestae de J. Grynnaeus, Franckfurt, 1646. Duplesis cita en el n. 164 de su bibliografía la colección de M. J. 
adagios y sus apéndices, con el objeto de facilitar al usuario la consulta de la recopilación de Erasmo.

Esta tendencia a convertir la colección de Erasmo en poliantea ${ }^{9}$ explica las numerosas y tardías ediciones, que proliferan hasta la mitad del siglo XVII, y en cierto modo, revela el infraentendimiento de los propósitos humanísticos de Erasmo en sus Adagia ${ }^{10}$. El refranero de Galindo se encuadra dentro de esta evolución. Según M. Mann Philips ${ }^{11}$ una de las razones de la inusitada difusión y celebridad de los Adagios está precisamente en la abundancia y variada erudición de sus glosas, acogida con fervor por un siglo que contempla entusiasmado las enciclopedias y compendios, proclives a la pedagogía humanista de la poetarum enarratio (Erasmo, De pueris, 121-124) ${ }^{12}$. El fenómeno de la cita tardía, como ha demostrado Ramírez Araujo, significa la paulatina transformación del adagio erasmiano, fuente doctrinal, en alusión retórica y lugar común. De este modo, en la época de las misceláneas y de las florestas, de los tesoros y de los calepinos, el libro de Erasmo expurgado por Manucio no es ya sino lo que nunca pretendió ser: un diccionario de citas clásicas $^{13}$.

No puede negarse la influencia erasmiana en la configuración del género paremiológico español. A partir de Pedro de Vallés, Refranes por el orden del $A B C$, Zaragoza, 1549, todos los coleccionistas de adagios españoles tendrán a gala el cotejo y la dependencia erasmiana. A propósito del refranero de Francisco del Rosal, Alfabeto de refranes, Córdoba, 1602, Busell Thompson afirma que la pretensión etimológica de las colecciones barrocas se fundamenta en la iniciativa erasmista de la que «se visualizan como continuadores de la obra y el espíritu de Erasmo» ${ }^{14}$. Los paremiólogos no consideran sus proyectos un pasa-

Gerlingii, Sylloge Adagiorum aliquo Desiderii Erasmi et aliorum juxta ordinem alphabeticam digestorum et germanico idiomate expressorum, Lugduni Batavonum, recopilación confeccionada sobre los adagios de Erasmo, bastante tardía, ya en 1649.

9 Para el uso sistemático de los adagios como ornato de la prosa latina cfr. el caso del libro escolar de Juan de Mal LARA, In Aphthonii Progymnasta Scholia, Sevilla 1567, estudiado por F. Sánchez y Escribano.

10 Cfr. M. MANn PhillPs, Erasmus on his time, Cambridge, 1980, vii.

11 Mann PhILIPS, M., The adages of Erasmus. A Study with Translations. Cambridge, University Press, 1980.

12 Erasmo, Declamatio de pueris, estudio crítico, traducción y comentario de J. C. Margolin. Travaux d'Humanisme et Renaissance, LXXVII, Droz, Ginebra, 1966.

13 R. Ramírez Araujo, «Los Adagia de Erasmo en los sermones de fray Alonso de Cabrera», Hispanófila, 11, 1960, 29-38. Cfr. A. Domínguez ORTIz, «Citas tardías de Erasmom, RFE, XXXIX, 1955, 344-350.

14 Francisco DEL RosAL, La razón de algunos refranes, ed. B. Thompson, Londres, Tamesis Book, 1979, p. 9. 
tiempo sino continuación de la descendencia clásica, especialmente, de la compilación erasmiana.

Con todo, M. Bataillon no cree que pueda hablarse de erasmismo a propósito de las colecciones paremiológicas glosadas del siglo XVII, aún cuando su espíritu sintonice aparentemente con el de Erasmo. No todo hombre culto que maneja los adagios es erasmista, aunque puede presumirse en él alguna simpatía por el filósofo cristiano ${ }^{15}$. En el terreno de la paremiología la dependencia erasmiana resulta excesivamente notoria como para ser relegada. Es cierto que las grandes cuestiones doctrinales pasarán inadvertidas en los refraneros áureos; pero se demuestra unilateralmente el empleo indiscutible de las sucesivas ediciones de los Adagia, en las distintas épocas, recurrencia que no pudo dejar de lado completamente temáticas, procedimientos de comentario, consideraciones teóricas sobre la paremiología, etc., hasta el punto de que la doctrina paremiológica castellana, puede apellidarse erasmiana.

La diferencia entre las colecciones romances y la de Erasmo ya había sido notada por Vallés. EI repertorio de Erasmo se ha formado desde las máximas literarias, vertidas por los moralistas, historiadores y poetas clásicos. El refranero español, objeto de la glosa, se ha compilado desde la tradición oral $^{16}$.

En Francia, Charles Bovelles emprende la continuación de los Adagios erasmistas. En España es Juan de Mal Lara quien continúa la tarea acometida por Erasmo para la lengua latina, aplicando la estructura y fines de aquella compilación a la lengua castellana ${ }^{17}$. Las glosas de Mak Lara siguen la colección de Erasmo en la variedad de la erudición, disposición formal en centurias, cierta flexibilidad ideológica, introducción de experiencias propias del autor, y el aglutinamiento de materia antigua y moderna; incluyen, también, como recordaba Menéndez Pelayo ${ }^{18}$, numerosos apólogos, cuentecillos, dichos agudos, fábulas esópicas, facecias y material folklórico. Es decir, la Filosofía vulgar, muestra el embrión de dos corrientes en el dominio paremiológico: influencia erasmiana, e intromisión de soporte folklórico en las glosas de los refranes. El prólogo consolidará en la paremiología castellana la costumbre de preludiar los refraneros con estudios paremiológicos inspirados en los Adagia.

${ }^{15} E$. y $E$, 811 . Si alguna vez lo citan es «con una frialdad más o menos hostil, o como a un autor de tantos", $E$. y $E, 773$.

16 L. COMBET, op. cit. 20, 48.

17 L. COMBET, op. cit. 152.

18 M. MenEndez PElayo, Origenes de la novela, III, en Obras completas, t. XV, p. 64. 


\section{ERASMO Y LAS FUENTES PAREMIOLÓGICAS DE LUIS GALINDO}

Entramos ahora en el problema de distinguir los elementos de cada fuente de las Sentencias filosóficas en relación con los Adagia erasmianos. Tras comprobar que el grueso del caudal paremiológico y del material erudito procede de los adagios erasmianos, y los repertorios de Mal Lara y Núñez, desechamos otro tipo de fuentes y utilizamos las siguientes fórmulas de reducción en el análisis ${ }^{19}$ :

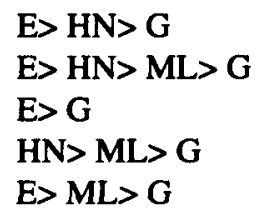

En la ponderación de la fórmula $\mathrm{E}>\mathrm{ML}>\mathrm{G}$ hemos partido del estudio de F. Sánchez Escribano, Los Adagios de Erasmo en la Filosofía Vulgar de Juan de Mal Lara, New York, Hispanic Institute, 1941, donde se cotejan los refranes malarianos con 166 citas explícitas o no de Erasmo. Comprobamos que el elenco de adagios proporcionado por Sánchez Escribano no es completo, pero, en todo caso, resulta suficiente para establecer una base comparativa de cara a nuestro propósito.

Las influencias E>HN y E>ML son paralelas en lo que se refiere a la recopilación de refranes, y si aceptamos las notas que definen el erasmismo en paremiología según la tesis de L. Combet: sátira anticlerical, burla de las ceremonias y prácticas exteriores de culto, instancia a la devoción sincera, en la medida en que estas notas pueden reflejarse en los refraneros ${ }^{20}$. Dado que ML recoge los refranes de $\mathrm{HN}$ con el propósito de rematar su comentario debemos buscar los rasgos erasmizantes en las glosas. En el caso de HN la extrema brevedad de comento restringe las posibilidades de glosa erasmista, que se ciñe al principio de selección proverbial. Esto signifca que la fórmula $E>H N>G$ se lee en la práctica como $\mathrm{E}>\mathrm{HN}>\mathrm{ML}>\mathrm{G}$, dado que el soporte erasmista recae principalmente en las glosas: de este modo, la posibilidad de influencia $\mathrm{HN}$ $>\mathrm{ML}>\mathrm{G}$ como préstamo erasmista se reduce al corpus de refranes: así pues, se han analizado los ejemplos en que se da el supuesto E> ML> G y E> HN>

19 HN: HeRnÁn NúNEZ, Refranes glosados, Salamanca, 1555; E: ERASMo, Adagiorum Chiliades Quattuor, Colonia, 1612; ML: Juan DE MAL LARA, Filosofia vulgar, 1568.

20 Op. cit., p. 140. 
ML> G. Ofrecemos algunos ejemplos. Para seguir el orden de versión en las distintas fuentes compartimentamos los textos en sectores designados por las letras, a, b, c, y sucesivas.

\section{Ejemplo 1. $E>M L>G$}

87B: A la hija la virtud, y al hijo el officio, no les puedes dar mayor beneficio.

E: $\quad$ Artem quaevis alit terra. Chil. 1. cent. 7. cp. 23.

$a$. Suetonis scribit, aliquando, $b$. Neroni praedictum a Mathematicis, fore, ut imperio destitueretur: $c$. unde vocem illam Neronis celeberrimam extitisse... quo majore venia meditaretur citharoedicam artem principi gratam, privato necessariam. $d$. Itaque cum intelligeret sibi pereundem, illud identidem dictitabat: Qualis artifex pereo. velut indignum esset qui tantus esse musicus, ut ubivis gentium vivere posset, nunc fame ad mortem adigi... e. Idem evenit Dionysio Syracusano tyranno, qui imperio exutus Corinthi ludum aperuit, ac pueros literas et musicam docuit.

ML: $b$. Nerón, aquel monstruo de crueldad, aprendió a tañer tan bien, $d$. que pudiera muy bien ganar de comer por ello, y dizen que lo hizo, porque a los principios que andavan por darle el mando, $b$. le dixo un mathemático como havía de ser despojado del imperio, y assí atreviéndose a su saber, dezía aquel adagio griego, que en latín suena, artem qua evis terra alit.. $e_{i Q u e ́}$ diremos de Dionisio Tirano, poderoso en Çaragoça de Sicilia, quando echado del reino puso escuela de enseñar a leer en Corinthio?.

G: a. <Sueton. in Nerone, cp. 40. Erasm. Chil. 1. cent. 7. cp. 33>. $b$. Este fue el consuelo de Nerón, que aviéndole pronosticado los Astrólogos, que perdería el imperio y vendría tiempo que se hallasse destituido, $a$. dize Suetonio, $c$. dixo muy confiado que a su destrezza y arte de la música, qualquier tierra y región en que se hallasse la socorreria, y assí no le podría faltar su officio. $d$. Este tanbién fue el refugio y socorro de que se valio aquel tyranno, hijo de otro e. Dionisio de Syracusa, (Val. Max. lb. 6. cp. fin) que auiéndole por sus crueldades depuesto del Reynado y hallándose a 
manos de la Fortuna, que él se fabricó, vn hombre particular, desterrado en la ciudad de Corintho, se acogió al ministerio que sabía y puso escuela pública enseñando a leer y escribir maestro de niños, obligado de la necessidad y pobrezza. Aunque se le notaba auer sido ambición y que ya no podía a los hombres, mandar y gobernar muchachos <Cic. Tuscul. 3. Vsque eo imperio caerere non poterat $>$. d2. Padre deste fue el otro Dyonisio, dize Plutarcho <Plut. de Fortun. Alexandr. orat. 2>.

Que siendo él peruersíssimo y viçioso, cuydó de ponerles a sus hijas todas, que tubo, los nombres de las Virtudes, Justicia, Honestidad, y Verguienza, pero no se puede adiuinar de sus costumbre de tan malvado padre que lo haría con los fines de nuestro Refrán...» f. $48 / 48 v$.

El orden de versión en Erasmo es: a, b, c, d, e.

El orden de versión en Mal Lara es el siguiente: b, d, b, e. No se cita la fuente de Suetonio.

El orden de versión en Galindo es a, b, a, c, d, e, y por asociación d. 2., aproximando la personalidad de los dos Dionisios.

La glosa de Galindo es más larga, incorpora muchos adagios y autoridades, se extiende a temas colaterales como las cualidades que deben reunir las mujeres nobles y plebeyas dadas en casamiento. Cita la conocida acción ejemplar de la prohibición de dote por Licurgo, el ejemplo de un personaje de Plauto, instruye en la conducta que deben observar para con los hijos las familias reales y las plebeyas, y dictamina las normas que deben seguirse con los primogénitos y con los segundones. Todas estas instrucciones se toman del adagio erasmiano. El orden de versión de Galindo sigue más fielmente, en fuentes y elaboración de sectores, el pasaje de Erasmo al que sólo corrige mediante ampliaciones.

\section{Ejemplo 2. $E>H N>M L>G$}

52B: Aquel hijo sabe / que conoce a su padre.

ML: El hijo sabe / que conoce a su padre.

HN: Interpreta el verbo saber, indicando que tal hijo «es sabio», pues dice ML «manifiesta culpa es no conoscer lo que se deve al padre, y gran locura no 
tener cuenta con lo que puede hazer el padre», cent. 7. refr. 31. La explicación alude al proverbio erasmiano, Matris ut capra dicitur. Chil. 2. cent. 10. cp. 14.

E: $\quad a$. Matris ut capra dicitur. b. In spurios dictum videtur, quorum $c$. pater incertusest, eaque gratia a matre denominantur. $d$. Ductum ab hoedis qui in caprilibus a matre dignoscuntur; nam a patribus hauquaquam possis... e. Manet etiam hodie vulgi jocus, quo dicunt; $f$. sapientem esse filium qui patrem suum norit. $g$. Hoc ab Homero manasse videtur, apud quem Odysseae primo, Telemachus rogatus, num Ulysses esset filius? respondet: ad hunc modum... $h$. Esse quidem illius mater me ait, est ego sane / Nescio, nemo suum patrem unquam noverit ipse.

ML: Entiéndese también que es sabio, que los cabritos son conocidos de la madre, y no del padre. Y assí los $b$. bastardos solían tomar el nombre de las madres, y alli trae Erasmo este refrán que se dize comúnmente. $h$. Sapientem esse filium, qui patrem suum novit ser sabio el hijo que conosce a su padre. g. Esto dixo Homero, haziendo a Telémacho, que preguntado si Ulixes era su padre respondió: «Ser su hijo, mi madre lo ha dicho, yo no lo sé, porque ninguno puede de veras conoscer quién es su padre». Y ser ésta difficultosa provança, las leyes lo dizen y arriba lo hemos tratado. De aquí ay algunos que, por esta causa, tienen más affiçión a sus madres, aunque es igual en conoscimiento si es matrimonio legítimo.

G: $\quad$ a. 51B: Hijo de su madre. b. Contra los espurios se toma vulgar est modo de dezir, $c$. porque ignorándose el verdadero padre, siempre de la madre toman el nombre, pues siempre es cierta. $a$. «Hijo de cabra», $d$. dezía el Griego por esta razón mesma, porque el cabritillo sólo la conoze a ella. Y de aquí $e$. por grazejo dezimos: Eum qui conjugem haberet adulteram veteres per caprum designabant, eratque apud illos hieroglificum hoc. Atque illud insuper ferebatur in spurios adagium, si de padre quispiam queritaret, vt. Matris quippe, vti capra, responderent. Pier. Valerian. lb. 10.

Pues siendo como vemos, $b$. la madre siempre çierta, quanto al padre todo es conjetura y mera pressumpçión legal como es porque nazió en casa, de lo que tenía por muger propria, porque le alimentó y le llamaua «Hijo», y éste a él «Padre», ésta es la prueba de la filiaçión, no porque aya otra çertidumbre más de la buena fee a fauor del matrimonio. e. Y assí como por juego nuestro Castellano califica de sabio al hijo que se attreuiesse a dezir, que conoçía 
quien fuesse su padre, pues más que sabio será gran adivino. 1. filium 6. D. de His qui sunt suit. etc. Mascard de Probationib. conclus. 788. et seqq. L. 1. gloss. \& tit. 14. Partid. 2. L. Lucius 83 D. de Cond. \& demostr.

$f$ : Tomóse este Refrán de la respuesta $e$. graziosa de Telemacho en Homero que affirma cómo no se halla hijo que seguramente pueda conozer y dezir con çertezza, éste es mi padre. Vsamos $e$. desta chanza verdadera, quando notamos que el niño comienza ya a reyr, y por el trato amoroso, que le haze el que le cría por suyo, se alegra y gorjea con él. Y entonzes como por alabanza y admiraçión del ingenio pueril, dezimos que $h$. sabe ya mucho, quando pareze que sabe, lo que no pueden alcanzar los mayores, que es conozer a sus padres. Esse quidem illius mater me ait: Ast ego sane / Nescio nemo suum patrem vnquam nouerit ipse. Homer. 1. Odyss. Incipe, paruepuer, risu cognoscere matrem. Virgil. Eclog. 4. in fin. $f$.

El orden de versión en Erasmo es: a, b, c, d, f, g, h.

El orden de versión en ML: $b, h$, $f$.

El orden de versión en G: a, b, c, a2, d, e, b2, e2, e2, e3, h, f, e4.

De este ejemplo se puede deducir:

La trascendencia de comentario de Núñez conduce a fundamentar toda la glosa sobre la ironía de la pretendida inteligencia del bastardo.

La versión de Galindo es la que sigue más fielmente a Erasmo, y aprovecha los mismos elementos de la versión para amplificar la glosa notablemente, reproduciendo insistentemente el elemento $e$, es decir, la nota jocosa pronunciada por Núñez La insinuación erasmiana hacia la interpretación jocosa del adagio se aprovecha extraordinariamente intensificada en Galindo.

La incertidumbre de la paternidad induce a Mal Lara a la glosa jurídica de la que parte el desarrollo del refrán en Galindo, inclinado siempre a las disquisiciones legalistas.

En el conjunto de los refraneros de Mal Lara y Galindo puede afirmarse que el empleo de la fuente erasmiana es muy distinto. Galindo cita abundantemente los adagios con precisión de lugar, en una proporción mucho más numerosa que la de Mal Lara, casi 200 proverbios por tomo. La recopilación erasmiana es aprovechada no sólo para el cotejo de los refranes castellanos con sus correspondientes latinos y griegos sino como repertorio de anécdotas, símbolos, autoridades y doctrinas, seguidas fielmente. El tratamiento de los Adagia como poliantea introduce, en la terminología galindiana, las autoridades del "Griego», suficientemente antiguas y dignificadas. En muchos casos Galindo realiza una versión libre de las glosas de Erasmo que le facilitan el recurso a 
otras fuentes paremiológicas: el apéndice de obras cortas que desde 1571 se añade a la compilación erasmiana.

\section{ERASmo y Luis GaLindo}

Resta ver el empleo directo que Galindo efectúa de los Adagios de Erasmo, fuente verdaderamente importante y copiosa de las Sentencias. Este estudio enlaza con la exposición de las fuentes paremiológicas latinas de la colección galindiana.

Este empleo se certifica en:
A) incorporación de adagios y cotejos;
B) tratamiento de los adagios censurados;
C) incorporación de doctrinas.

\section{A. Incorporación de adagios y cotejos}

Apenas nos detendremos en este punto. Se trata, en definitiva, además de los ejemplos aducidos anteriormente, de las concordancias perfectas o traslados literales desde los adagios de Erasmo tanto para la incorporación de nuevos refranes, como para su cotejo con la lengua clásica. La mayor parte de los apotegmas referidos se toman de las glosas de los Adagia, como también las citas y tópicos del estoicismo. Entre los ejemplos de calcos textuales hemos recogido 158 traducciones de los adagios erasmianos, y procedentes también de los apéndices de la recopilación. Seleccionamos aquí sólo algunos ejemplos.

Cuando Luis Galindo quiere comparar expresamente el refrán con Erasmo no omite la paremia. En los otro casos lo utiliza como argumento de autoridad:

485A: La Antigüedad pintó desnudas a las Gracias. «Chil. 2. cent. 7. cp. 5O. Nudae Gratiae».

El empleo de Erasmo como fuente o poliantea se patentiza en estos ejemplos: 
472A: Testa diu. Horatius lb. I. epa. 2. Unde Erasmus. Chil. 2 cent. 4. cp. 19.

473A: Plutarch. Symp. l. q. 5. Unde Erasm. Chil. 1. cent. 2. cp. 92.

478A: Por amor del buey, lame el lobo el yugo. El catalán, por amor del bou, / llega lo llop el jou. Chil. 4. cent. 7. cp. 91: Ut lupus ouem amat.

En algunos casos la variación del adagio clásico al refrán castellano es mínima, una simple actualización:

Mucha paja y poco grano, / vicio es del mayo, 254A2. E multis paleis parum fructus legi. Chil. 1. cent. 2. cp. 75.

Como sembrares así recogerás 101B. Ut sementem feceris, ita et metes. Chil. I. cent. 8. cp. 78.

Sustentarse del aire. Vivire du vent. 191A. Vento vivere. Chil. 4. cent. 9. $c$ p. 3.

Dar alas. 214A. Alas addere. Chil. 4. cent. 8. cp. 86.

Hacer del diablo, dos endemoniados, 627D. Daemonem daemone pellere. Petr. Godofred. Adag. 11.

Si a tí te agrada, / a mí no me desagrada. 142A. Si tibi non molestum, et mihi iucumdum est. Ex. Brassican. Proverb. cp. 120.

Un asno entre muchas monas, / le cozean todas. 669A. Asinum inter simias. Chil. 3. cent. 5. cp. 41.

Mitior columba. Chil. 3. cent. 6. cp. 46 Más manso que una paloma., 35P.

Virgula. Chil. 1. cent. 1. cp. 92. Tiene el mando y el palo, 34P.

Pulchre dixisti. Belle narras, Chil. 1 cent. $10 \mathrm{cp}$. 55 . Lindamente lo parla, 142P.

Cumini sectior Chil. 2 cent. 1. cp. 5. Partirá un comino, 14SP

\section{B) Tratamiento de los adagios censurados. Monachatus non est pietas}

El único tema que enlaza plenamente con la sátira anticlerical de Erasmo en el ms. de las Sentencias es la censura de la hipocresía y vana observancia. 
Las glosas sobre este particular son numerosas y se dirigen a probar, por una parte, que la observancia puramente exterior de la práctica religiosa es una especie de superstición, y de otro lado, lo que Cervantes explicó en la conocida frase «Bien predica, quien bien vive» $(D Q, \mathrm{II}, 20)$.

El escrúpulo y la hipocresía frustran la caridad, verdadera ley de Cristo, virtud que comienza por el cumplimiento de los propios deberes como declara la doctrina estoica: Estad en esto. Cumplir lo debido. La verdadera caridad «no se entiende sólo en dar una limosna al pobre mendigo», mientras que se conservan rencores y se retiene el pago de las deudas, ni puede ser bueno quien «es duro en la remisión de la ofensa, largo en la satisfacción de sus acreedores y blasona de caritativo». 352C, f. 131 .

Con diversas imágenes y tonos, desde lo más familiar a lo más grave ${ }^{21}$, los signos que procuran la descripción del hipócrita marcan la distancia entre lo real y lo aparente ${ }^{22}$. Así, la manzana que oculta el gusano es símbolo de la hipocresía, como el follaje hueco de los árboles, los frutos acedos, el canto de las aves, el traje, insignias, cogullas y hábitos de profesión virtuosa, figuran la bondad y no la presuponen.

Incluso en tema tan favorable a la nota erasmizante, mientras algunos refranes se acercan a la clara pintura erasmiana de la piedad falsa, otros omiten deliberadamente el comentario que a todas luces imponía la glosa anticlerical. Esta dualidad de posturas se mantiene con respecto a temas candentes, como la murmuración, la obediencia al rey, y a la Inquisición ${ }^{23}$, el escrutinio de las lecturas, la naturaleza de la fe, etc. Se incluyen refranes que son ejemplo de un

21 149C: No entra en Misa la campana / y a otro llama «del que aconseja el bien a otros que no toma para sí», f. 57 junto a 33H: Sepulcros blanqueados, / Muladares nevados. Fr. Sepulchres blanches. «Retratos muy parecidos son del hipócrita por fuera lucientes, y por dentro feos y oscuros. La superficie hermosa y el interior asqueroso y horrible, virtud aparente $y$ vicio encubierto». $f$. $203 v$.

22 332H: Por las obras, no por el vestido, / el hipócrita es conocido. E cantu dignoscitur avis. Chil. 4. cent. 12. cp. 21. aliud in titulo, aliud, in Gilb. Cognat. cent. l. Adag. 1. 323H: De Dios hablar, y del mundo obrar, 330H: El rosario en la mano, $/$ y en la faltriquera el diablo. «Retrato vulgar del hipócrita en que gracioso se nos pinta el que muestra devoción y virtud exterior y en el interior oculta el autor de la impiedad y vicios».

${ }^{23}$ Con el rey y la lnquisición / chitón. «... demás de ser mal seguro lo hablado por los parliculares en estas materias secretas, se tiene justamente por especie de trayción y temeridad sacrílega culpar acciones y juzgar mal de los hechos y disposiciones del superior. Quando se consulta sobre lo que convendría al príncipe, libre ha de ser el voto que se pide, mas en lo que tiene executado o resulto attreuimiento de la soberbia sería la contradicción y juiçio opuesto Ley. Cod. de Divers. rescript», en $81 \mathrm{C}$, y en 111R: "En las cosas de la fe santa no hay burlas en lo hablado, ni es la excusa segura en decir que fue por juego la que es heregía o proposición temeraria y excandalosa». 
pensamiento escéptico y racionalista, con frecuencia procedentes de la lengua francesa, y a pesar de las dificultades que su proposición comporta, Galindo consigue defender, una y otra vez, la ortodoxia del comentario ${ }^{24}$.

No está, con todo, la insinceridad del hipócrita en su porte externo sino en la falsía de sus obras. En el ejemplo del refrán 203C2: El hábito no hace al monje, que el francés dice, L'abit ne fait pas le moyne, tan propicio a la cita erasmiana, se concluye, sin embargo, con 1a referencia a la inadecuación entre obras y apariencia, tomando una cláusula legal, habitus non facit viduam, sed pudicitia vidulis. L. 15. Codic. Ex. qq. Caus. infam. cuando correspondía nombrar el conocido adagio monachatus non est pietas. La glosa se realiza sobre un pasaje de S. Juan Crisóstomo, mejor recomendado doctrinalmente:

Y assí se dize del que no vive como professa, representa religión y obra secular. Muchos somos los sacerdotes, y pocos los sacerdotes, dize Chrisóstomo. Muchos en el nombre y hábito, pero pocos en el cumplimiento de su obligación. Jáctanse contentos de las exterioridades y en lo interior son opuestos y ajenos. loc. cit.

En este refrán, por si fuera poco, se ejemplifica con un apotegma clásico, no religioso, el dicho de Epaminondas tebano, que por su virtud pudo rehabilitar un oficio humilde. Aristipo, extiende esta discordancia a las vanas apariencias de la honra social, en la disputa por el asiento en el convite. f. 7Sv. Y por último, Luis Galindo amplía el comentario de forma que englobe cualquier circunstancia de hipocresía:

No todos los que estudian son letrados, ni los que van a la guerra soldados, ni el que consigue insignias de Academia es docto, no hace noble al plebeyo el hábito, ni son doncellas todas las que andan en cabello, no

24 281A: El hombre cree y el alma, duda, del portugués, Ho homen cree, e alma duvida. 281A: En mi no está, lo que en mi alma no esta. A may nest ce que en mon ame nest. Podemos apreciar un tinte esceptico en la insistencia con que se afirma la incapacidad cognoscitiva del hombre en este mundo, matiz frecuente entre los necestoicos de este siglo, 177F: «Puede también por este castellano teólogo y philosóphico entenderse que assí como las cosas que la fe nos enseña, ser verán en el cielo claras, y las que ahora son esperanzas, entonzes serán posessión. Assí en las humanas, en que de presente se opina y nada se sabe, sino es lo que la fe determina, la verdad tanbién del todo se nos manifestará en el çielo, y lo que aora es opinable tendremos entonzes, çientíficos, çierto y sin duda». $\mathrm{f} 95 \mathrm{v}$. 
todos los racimos son vino, ni todas las esperanzas de los hombres llegan a granar. loc. cit.

Así, el comentario anticlerical se despliega en un comentario desengañador de la falsa apariencia.

El refrán 108C: $O$ calzad, como vestís / o vestid como calzáis se aplica la discordancia a «los desiguales en sus acciones y que no conforman sus hechos con sus palabras, cuando vemos que en uno proceden muy ajustados y estrechos de conciencia y en otro muy libres y disolutos» que cuadra según Galindo, no sólo al hipócrita sino al «mentido filósofo». De nuevo el recurso al argumento estoico sirve para salvaguardar un comentario anticlerical: «Y en quien Séneca "epa. ad Lucill. 20" pide esta consonancia de las obras con lo hablado, y $\mathbf{S}$. Jerónimo en las viudas y su hábito».

Los comentarios aparentemente erasmistas, analizados en profundidad revelan un seguimiento más estrecho de la fuente, que no ha calculado las posibilidades significativas, y no suponen intencionalidad reformista.

En el refrán 52C: Caído del cielo, la glosa califica el refrán de «exageración milagrosa» el tiempo feliz en que se alcanzase «un buen prelado, un buen rey, o para la reformación de costumbres, un predicador apostólico, y un sujeto aventajado en santidad y virtud conocida», f. 19v. La aparente añoranza de buenos pastores no es sino un traslado del adagio Caelo delapsus. Gilbert. Cognat. adagior. cent. 2. cp. 172.

En el adagio Dulce bellu inexpertis. Chil. 4. cent 1. cp. 1, nota del refrán 708C: Quedan mancos o cautiuos / quando quedan vivos la glosa denuncia los frutos de la guerra y previene al soldado novel a la pérdida de la libertad o la vida.

Cae el mísero soldado en las (manos) del enemigo, que vsando con él de aiguna humanidad, a su parezer, le conserua prisionero, cautiuo, y otras vezes sale estropeado y manco de las heridas y de aquí, como en abominación, y para retraher a los hombres de propensión arresgada y loca, y en especial, los manzebos, quien pareze dulze el orgullo de la milicia, porque no han experimentado sus penalidades y peligros, les amenaza con los sucçessos más comunes.

La aplicación moral de este adagio atañe a los que «entran noueles al matrimonio y otros negocios humanos en que las entradan combidan, y las expe- 
riencias desengañan». f 160, 236G: ¿A dónde váis?. A la guerra. / ¿De dónde venís?. De la guerra atenúa la fuerza de la diatriba antibelicista de Erasmo. Aunque otros lugares de Galindo evidencien el elogio de la paz puede decirse que es otro el punto de vista adoptado: el florecimiento de las artes es obra de la concordia y paz entre los hombres, motivo que se acerca más al presupuesto estoico de la tranquillitas, representado frecuentemente en la emblemática ${ }^{25}$. Otro tanto puede decirse del adagio Sileni Alcibiades que brevemente se refiere al paradójico contraste entre la verdad y la apariencia, estoico enfrentamiento del conocimiento y la opinión.

\section{C) Incorporación de doctrinas}

La línea maestra del comentario religioso en los refranes de Galindo ofrece las siguientes posibilidades:

En los temas recurrentes de la sátira erasmista encontramos ya no ambigüedades, sino verdadera contradicción de aquellas tesis, como en la aprobación de las reliquias ${ }^{26}$, el elogio del recogimiento del fraile analizado desde el punto positivo de virtud, y no como ejemplo negativo ${ }^{27}$ La cuestión de la interioridad de las prácticas religiosas, orientadas al fervor del corazón, la brevedad de la oración, que no se refiere a la brevedad del tiempo dedicado sino al defecto del que «atropella y se cansa con el ejercicio», se tratan en los refranes de Galindo con cierta confusión. Por una parte corrobora el autor la necesidad de esa devoción íntima, "Y con mayor razón en la oración y ruegos para con Dios, que no se mueve como los hombres y atiende más a el corazón que a las vozes, y a las instancias», por otra, no intenta recortar sus tiempos. La piedad y

25 Alciato, 187, 177, 178; Hadriano Junio, 6; Covarrubias, 74; Solórzano, 94 y Fajardo, 74.

26 1335C: Honra es de los amos, la que se haze a los criados... «La veneraçion a las reliquias de los santos es en gloria y honra de Dios, cuyos siervos fueron». F. 212 v, doctrina de S. Jerónimo: Adversus Vigilantium epa. 53 in princip. Honoramus seruos, ut honor eorum redundet ad Dominum.

27 1329C: El mexor criado, y el mexor fraile, /el que menos sale. Quod piscis in arido, hoc monacchus in oppido. D. Antonio, Abad apud Niceph Caliist. f. $211 \mathrm{v}, 39$ O: Frayle que su regla guarda/toma de todos y a nadie da nada. «Lo que en el religioso se dize por alabanza, que rezibe de todos; pero sin liçençia del superior no puede dar, dezimos por oprobio y vituperaçión del avaro, muy fáçil al recebir de cualquiera y çerrado para todos». f. 4v. 133 E: Ny rey traydor, ny Papa excomulgado. 323F2: Fraile de soldado, es el más apartado; 324F: Fraile de noche, hildago de dia. Yy villano en quadrilla. 323F2: No ay peor abad, que el que monge a estad. 
los deberes son totalmente compatibles ${ }^{28}$. La oración para que sea aceptable a Dios «debe subir brevemente al cielo» 2410.

Incluso en algún ejemplo se constata una actitud opuesta a la de Erasmo, como en materia de ceremonias y protocolos, donde Galindo aprueba prácticas antiguas.

81C: Besar la tierra que otro pisa... Acción del más humilde reconocimiento del beneficio y señas de profunda veneración devota. Costumbre fue del Asia, besar la tierra el vasallo que entraba a hablar a su rey, y uso de los moscovitas, como entre nosotros besar el pie al Pontífice Sumo y la mano al príncipe en... muestras de vasallaje.

En lo referente a los lutos Galindo insta, en razón de su tendencia estoica, a la moderación y templanza. Para quien acepta la voluntad divina, y saca bienes de los males no tienen sentido las manifestaciones aparatosas de dolor, de aquellos que se dejan crecer el cabello, se ausentan de la mesa, o no encienden la lumbre en la casa.

1001: En la Iglesia cantar, y en casa llorar. Los duelos y llantos públicos por los amigos muertos prohíbe este refrán, como la razón y la ley los abomina; porque las oraciones y sufragios son, y no las lágrimas los que aprovechan al difunto. Natural es el asentimiento en la falta de quien bien se quiere, pero las demostraçiones exçessiuas fueron siempre imprudentes y gentílicas, f. $247 \mathrm{v}$.

Con todo, a propósito del refrán 305B: A boda ny baptizado / no vayas si no es llamado, nuestro escritor aprueba como más útil, «la ida a la casa del llanto y mortuorio, que a la del combite, y alegrías». La razón de esta incoherencia está en el deseo de plegarse a la sentencia conocida, del Eclesiastés, cp. 7 Melius est ire ad domum luctus, quam ad domum conviji ${ }^{29}$.

28 140C: Misa ni febada/no estorban jornada. Otros dizen: Por oir misa, y dar cebada/nunca se perdió jornada. «...y en quanto a la devoçion de que christianamente haze memoria justa nuestro refrán, es persuasión y advertençia piadosa de que ny el tiempo, ny la edad nos corre en el entretanto que ocupamos diligencias y asistimos al sacrifiçio de la Misa, y que ni allí se rompen ni envejezen los vestidos que llevamos, cuánto menos, pues por devosión tan breve, se nos retardara el viaje y jornada?». f. 54.

29 Un ejemplo de adaptación de costumbre gentilica a cristiana reflejan los siguientes proverbios: 4G: «Quanto a la memoria de amigos difuntos algunos de la gentilidad (Chil. I. cent. 2. 
Son muy escasos los refranes anticlericales seleccionados por las Sentencias filosoficas. Pero aún en el caso del refrán antifrailuno o anticlerical, procedentes como es lógico de Núñez, los comentarios de signo negativo suelen eludirse acudiendo a varios procedimientos. El comentario se puede extender a un grupo más amplio de sujetos censurados, grupos no clericales: puede también entenderse buscando su filiación antigua en el mundo clásico, lo que excluye la sátira clerical, o bien entroncando la sátira dentro de lo burlesco.

202E: Debajo de lo pardo está el engaño, que se aplica no a la orden franciscana, sino al rústico labrador.

35A: Nunca vi de cosa menos, / que de abriles y obispos buenos.

272F: Lo que no lleva Christo, lleva el Fisco. (Mal Lara, cent. 2. r. 18). Quando vemos los bienes del avaro, que ni daba una limosna ni pagaba diezmos, ni deudas en poder de ministros de / justicia confiscados por algún delito de mal adquirido. Y que lo que abía de ser restitución a los dueños se distribuye en penas y costas de procesado usamos de este refrán tomado de $\mathbf{S}$. Agustín, y referido cp. 8. 16. q. 7. in Decr. Guilelm. Benedict. in cap. Raynunt. de testam. ver. Mortuo. 1. n. 143. (Quod non capit Xtus, rapit Fiscus) f. 108/108v.

Los comentarios anticlericales de sentido burlesco podrían asociarse a la tendencia erasmista que sembró sales y gracejo en los ambientes sacros. Es el caso de refranes y anécdotas como Desnudar un santo, / para vestir otro., 158D3. Nudere Petro, Paulum tegere. Gilb. Cognat. cent. 3. Adag. 274. «Tomado de los sacristanes que para la celebración de una fiesta descomponen un altar para el adomo de otro». Si tenemos en cuenta que la figura del sacristán es un prototipo folklórico del universo cómico, podremos corroborar lo inofensivo de estos y otros ejemplos ascéticos, célebres y patrimoniales en la literatura religiosa, de los que sólo podemos extraer un chascarrillo anticlerical célebre, práctica-

cp. 52. Vivorum oportet meminisse) la tuvieron por ominosa y no quisieron que se hubiese de hablar ni traer a la conversación sino los vivos, y que se dejasen en su descanso a los muertos. A cuya superstición miraba la fábula de Letheo». 338A: «Otros más humanamente y de verdad amigos afectaron esta memoria tanto que para su perpetuidad usaron de retratos y grababan sus nombres en los anillos y vasos en que de ordinario bebian para traer al amigo difunto en la manera que podian presente siempre. Y nosotros cristianos por consejo de la Iglesia santa tenemos por santos y saludable la memoria de los muertos, prueba de amistad legítima y a nombre de ellos se nos pide y demanda a todos, en especial a los amigos vivosn. f. 20. 
mente inocuo, a propósito de la abstinencia cuaresmal: la murmuración contra los cortesanos de Madrid que no guardan ningún tipo de precepto:

En abominaçión y para dissuadir este abuso se cuenta vn caso vulgar. Llegaron a comer vn dia de los prohibidos de carnes a vna hosteria y casa de gula vna quadrilla de passajeros en vn pueblo de Franzia, y preguntándoles qué gustaban de que se les siruiesse a la messa, si carne, o si pescado, respondieron que sacassen de pescado. Entonzes el huesped dixo en voz baja a los de su casa: «Estos sin duda son catholicos, papistas». Llegó despues otra quadrilla y preguntándoles lo mesmo dixeron: «Traygan / de carne». Y el huesped repitio a los suyos como antes: «Ola, estos son Lutheranos». Vino vitimamente a la messa otra tropa y preguntándoles lo que a los demás respondieron: «saquen lo que vbiere de carne y de pescado». A que dixo y repitió a su gente el huesped: «Estos son de Madrid, y cortesanos que no reparan en filaterias». 356C, f. 132v/133.

El tema del ayuno, y la penitencia en los tiempos fuertes de la Liturgia se toca con gracejo ${ }^{30}$ y no con acrimonia: deriva de la proposición que los refranes populares imponen, Con quien la auéis Cuaresma, y aboceta el perfil cómico del que finge achaque por no guardar ayuno, del que ayuna porque no puede en realidad comprar carne, aunque en ciertas ocasiones reviste un tono severo ${ }^{31}$.

336C: La cárzel y la Quaresma / para los pobres parezen hechas ...la Quaresma comunmente la observa / el pobrecillo, porque el rico, o le busca achaque, o la defrauda con los regalos, engañando el ayuno y la abstinencia: no tiene por juicio temerario ni vana conjetura, persuadimos a que la penalidad de las cárçeles, la prohibiçión de las carnes y preçeptos del ayuno parezen inventados y sólo impuesto para pobres.

30 Achaques al viernes, por no ayunar. 44A: El que caldo sorbe/ny ayuna, ny bebe, ny come, comentado «Si fuera texto canónico este refrán aúamos hallado gran prueba contra el uso del chocolate, en que se disputa sobre si quebranta o no el ayuno eclesiástico...». 210A. A propósito del vicio de la gula: El çebo es el que engaña,/no el pescador, ny la caña. $711 \mathrm{C}$ : Más largo que el sábado santo. 55L.

31 Se censuran los ayunos continuados, como los antiguos de Traspaso, que duran tres días consecutivos. cp. 18 et seqq. De Consecrat. distinct. Y el refrán Poca çiençia y mucha consçiençia. 807C, o Consçiençia de theólogo. 
Muchos refranes que hubieran dado lugar al comentario erasmizante suscitan en Galindo el interés por cuestiones puramente teológicas o jurídicas.

634A: De hombres es errar, / y diabólico perseverar, refrán que brinda la oportunidad a las comparaciones de Verino entre la penitencia y el salvamento feliz tras el naufragio.

114D: Dar fraterna sobre la práctica de la caridad.

373D: El hecho malo, / al alma y al cuerpo trae daño, pues el pecado hiere no sólo al alma sino también al cuerpo, y el delito apareja siempre su propio castigo en el arrepentimiento.

391D: Obras hechas en pecado.

Las menciones proverbiales, fruto de la cultura cristiana, constituyen, a su modo, apotegmas y dichos célebres de la catolicidad, y hasta cierto punto imitan la manipulación proverbial que Erasmo operó dentro del corpus de los adagios greco-latinos.

El ms. constata numerosas supersticiones y costumbres antiguas que se eximen en favor de la dignidad de un proverbio, o de una costumbre cristiana. La proposición de costumbres antiguas había tenido su razón en los Adagios de Erasmo como prueba de natural en las costumbres loables, y también como refutación de prácticas paganas heredadas por la costumbre cristiana. La coloración de los textos aducidos se demuestra neutra en las glosas de las Sentencias.

142V: Folium Sybillae. De aquí es la loable costumbre antiquísima de que todas las obras se comiencen en el nombre de Dios, y premisa la invocación divina: persuadidos los que obran justamente a que por este principio y medio se le seguirán fines buenos. Y el mesmo Dios verdadero nos enseña que es y debe ser en todas las cosas el principio, medio y fin de todas las cosas... $Y$ de aqur fue la superstición gentflica de no comenzar acción alguna sin tomar agüero de ella, que llamaron auspicio.

933C: Dios delante el mar es llano. Port. Deus diante he o mar chao.

927C: De aquí los poetas y escritores invocaron su Nombre. $Y$ a este fin la religión cristiana desde las primeras letras puso la Cruz insignia de Cristo por adalid de su abecedario, y con la primera señal en su orden f. 129v. 
En otras ocasiones, la apelación a las costumbres supersticiosas no tiene más objeto que mostrar el paralelismo lingüístico entre un adagio clásico y un proverbio castellano. Así, en la expresión «Algún ángel habló en él».

Mercurius supervenit. Chil. 4. cent. 4. cp. 91, cristianizada en «habló un ángel», al espacio vacío en la conversación de varios. 256L

También se censuran las prácticas de la gentilidad ciega, y sus creencias.

\section{Conclusión}

A pesar de tan estrecha relación de fuentes y estructura entre las Sentencias y los Adagia, son pocos los resabios erasmianos que perduran en las glosas de Galindo. Obedecen, en general, a traslados literales que no han calculado bien sus posibilidades de ambigüedad. Luis Galindo utiliza a Erasmo con mayor abundancia que sus predecesores del siglo XVI. Sin embargo, es éste, en palabras del profesor A. Vilanova, un erasmismo sin Erasmo. El recurso de este refranero a la erudición erasmista confirma las tesis controvertidas sobre la permanencia del holandés en España en el siglo XVII. La dependencia erasmiana no es sino un modelo estructural. 